\title{
Global observations of electromagnetic and particle energy flux for an event during northern winter with southward interplanetary magnetic field
}

\author{
H. Korth ${ }^{1}$, B. J. Anderson ${ }^{1}$, J. M. Ruohoniemi ${ }^{1}$, H. U. Frey ${ }^{2}$, C. L. Waters ${ }^{3}$, T. J. Immel ${ }^{2}$, and D. L. Green ${ }^{3}$ \\ ${ }^{1}$ The Johns Hopkins University, Applied Physics Laboratory, Laurel, MD, USA \\ ${ }^{2}$ Space Sciences Laboratory, University of California Berkeley, Berkeley, CA, USA \\ ${ }^{3}$ School of Mathematical and Physical Sciences, The University of Newcastle, Callaghan, NSW, Australia
}

Received: 6 October 2007 - Revised: 25 January 2008 - Accepted: 26 March 2008 - Published: 11 June 2008

\begin{abstract}
The response of the polar ionospherethermosphere (I-T) system to electromagnetic (EM) energy input is fundamentally different to that from particle precipitation. To understand the I-T response to polar energy input one must know the intensities and spatial distributions of both EM and precipitation energy deposition. Moreover, since individual events typically display behavior different from statistical models, it is important to observe the global system state for specific events. We present an analysis of an event in Northern Hemisphere winter for sustained southward interplanetary magnetic field (IMF), 10 January 2002, 10:00-12:00 UT, for which excellent observations are available from the constellation of Iridium satellites, the SuperDARN radar network, and the Far-Ultraviolet (FUV) instrument on the IMAGE satellite. Using data from these assets we determine the EM and particle precipitation energy fluxes to the Northern Hemisphere poleward of $60^{\circ}$ MLAT and examine their spatial distributions and intensities. The accuracy of the global estimates are assessed quantitatively using comparisons with in-situ observations by DMSP along two orbit planes. While the location of EM power input evaluated from Iridium and SuperDARN data is in good agreement with DMSP, the magnitude estimated from DMSP observations is approximately four times larger. Corrected for this underestimate, the total EM power input to the Northern Hemisphere is $188 \mathrm{GW}$. Comparison of IMAGE FUVderived distributions of the particle energy flux with DMSP plasma data indicates that the IMAGE FUV results similarly locate the precipitation accurately while underestimating the precipitation input somewhat. The total particle input is estimated to be $20 \mathrm{GW}$, nearly a factor of ten lower than the
\end{abstract}

Correspondence to: $\mathrm{H}$. Korth

(haje.korth@jhuapl.edu)
EM input. We therefore expect the thermosphere response to be determined primarily by the EM input even under winter conditions, and accurate assessment of the EM energy input is therefore key to achieving a comprehensive understanding of the I-T system, particularly during active times when the energy input increases markedly and expands well equatorward of nominal auroral latitudes.

Keywords. Ionosphere (Electric fields and currents; Ionosphere-magnetosphere interactions; Particle precipitation)

\section{Introduction}

The interaction of the solar wind with the Earth's magnetic environment in space gives rise to an electromagnetic dynamo that is coupled to the ionosphere-thermosphere (I-T) via electromagnetic fields, currents, and particle precipitation. This coupling results in tens to hundreds of gigawatts of power input to the high-latitude I-T (e.g. Anderson et al., 1998; Sharber et al., 1998; Burns et al., 2004). During intense storms the power may rise to nearly a terawatt ( $\mathrm{Lu}$ et al., 1998). Climatological estimates for this energy input have been obtained with statistical studies (e.g. Hardy et al., 1989, 1991; Gary et al., 1995). The fact that the system responds within tens of minutes to changes in the interplanetary magnetic field (IMF) (Murr and Hughes, 2001) implies that the statistical results may not represent any actual state of the system since they represent amalgams of observations for many different situations. Consequently, the statistically derived climatologies are probably insufficient to describe the actual distribution and intensity of the energy input to the I-T system. Thus, to understand the true consequences of

Published by Copernicus Publications on behalf of the European Geosciences Union. 
the energy transfer into the I-T system, one needs to obtain globally distributed measurements of the actual high-latitude energy input for specific events.

The two major mechanisms of energy input at the topside ionosphere are particle precipitation and electromagnetic (EM) power or Poynting flux. Precipitating particles deposit their energy in ionization through collisions in the ionosphere, enhancing the ionospheric density and conductivities, and heating the ionosphere (Roble and Rees, 1977). Electromagnetic energy incident on the topside ionosphere is either dissipated as Joule heating (e.g. Cole, 1962, 1975) or converted into mechanical energy of the neutral winds (Fujii et al., 1999; Thayer, 2000). To understand the I-T response one must characterize both inputs. Particle precipitation and EM energy flux have different spatial distributions, and previous studies suggest that the latter commonly exceeds the former by about a factor of about four in total power (Richmond and Kamide, 1988; Lu et al., 1995, 1998; Anderson et al., 1998).

We understand the particle energy input better because measurements of precipitating particle fluxes and the consequent auroral emissions have been conducted for some time. Particle precipitation can be measured directly by spacecraft at altitudes between the ionosphere and the auroral acceleration region (Haerendel et al., 1994; Newell, 2000) and can be inferred by auroral luminosity (e.g. Rees et al., 1988; Lummerzheim et al., 1997). Converting luminosity to energy input requires knowledge of the precipitating species and the spectral character of the incident particles (Germany et al., 1994). The reliability of energy deposition estimates can be further improved by using observations in multiple UV bands.

Electromagnetic energy input is more difficult to measure because it requires both electric and magnetic field observations. The most reliable determinations use in-situ magnetic and electric field (or plasma drift) measurements from low-altitude satellites, which are combined to estimate the Poynting vector (Gary et al., 1994, 1995; Mishin et al., 2003). The advantage of this approach is that the measurements are sampled closely in both space and time so that the obtained Poynting vectors represent instantaneous observations. However, single satellites give information only along the satellite track and cannot "image" the EM input to yield the distribution of incident power. Global distributions of the largescale parallel Poynting vector, providing a complementary perspective to in-situ observations, have recently been evaluated from measurements of the magnetic perturbations at the ionosphere by the constellation of Iridium satellites and observations of the ionospheric electric field by the Super Dual Auroral Radar Network (SuperDARN) (Waters et al., 2004).

The Iridium constellation consists of more than 70 satellites distributed over six 780-km circular polar orbit planes. Each satellite is equipped with an engineering magnetometer providing magnetic field measurements with 30-nT digitization resolution and noise commensurate with the least signif- icant bit (Anderson et al., 2000). Because the engineering uses for the data only require coarse time resolution, the time interval between telemetered samples on an individual satellite is roughly three minutes. For this reason, global distributions of the magnetic perturbations are obtained using observations accumulated over intervals one or two hours long (Anderson et al., 2000). These data are routinely used to derive global distributions of the large-scale Birkeland currents and globally distributed maps of the magnetic perturbation field, $\boldsymbol{b}$, above the ionosphere by applying a spherical harmonic fit to the perturbations (Waters et al., 2001).

The Northern Hemisphere SuperDARN network consists of nine HF radars in the polar region providing coverage over more than twelve hours of local time (Shepherd and Ruohoniemi, 2000). Technical details of the radars are described in Greenwald et al. (1995). In common mode, the radars scan through 16 successive azimuthal directions or beams spaced by $3.3^{\circ}$, with an integration time of $7 \mathrm{~s}$ per beam (Ruohoniemi and Baker, 1998). The Doppler shifts in the backscattered returns provide estimates of the plasma velocities, which are used to derive the electric field, $\boldsymbol{E}$. The radars rotate with the Earth. For integration into the analysis of EM flux using Iridium data, the effect of corotation is removed from the velocity measurements by subtracting the projections of the radar velocity along the lines of sight. The resulting velocities and, hence, electric fields are evaluated in an Earth-centered, non-rotating frame.

A recent study by Korth et al. (2005) compared distributions of EM and particle energy flux during an interval of northward IMF. Because the event occurred during Northern Hemisphere summer and the Birkeland currents were located poleward of $75^{\circ}$ invariant latitude, the ionospheric region of EM energy input was in sunlight. It was therefore possible to estimate the Poynting flux from the global distribution of magnetic perturbations obtained from the Iridium constellation by using a solar-EUV based conductance model to estimate the convection electric field. The DMSP satellites provided tracks through the region of interest and the conductance was scaled to yield results in agreement with DMSP drift meter observations. The global estimates of magnetic perturbations were also compared against the in-situ observations by DMSP to derive adjustment factors for the Iridium-derived magnetic perturbation distribution. Simultaneous IMAGE FUV observations showed a single prominent emission co-located with the NBZ-system upward current. The particle precipitation estimated using IMAGE FUV together with DMSP particle data was $6 \mathrm{GW}$ while the total EM energy input was $51 \mathrm{GW}$, about eight times greater. Although the EM energy input was confined to latitudes poleward of $78^{\circ}$, the hemispheric power was similar in magnitude to that observed for southward IMF conditions by Waters et al. (2004). We note, however, that the Waters et al. work did not derive correction factors using comparisons with insitu observations of both $\boldsymbol{E}$ and $\boldsymbol{b}$, so it is possible that their results underestimate the actual EM input. 
The findings of Korth et al. (2005) were dramatically different from climatology estimates for the energy input and reflect the need to evaluate the energy transfer for specific states of the system. Here we extend this work to simultaneously evaluate particle and EM energy input for an event during southward IMF and with the ionosphere in darkness. The interval of interest is from the Northern Hemisphere from 10:00-12:00 UT on 10 January 2002. The approach to estimating the convection electric field from the magnetic perturbations used in Korth et al. (2005) cannot be applied when the ionospheric conductance is not dominated by solar EUV because the uncertainties in model estimates for the particle contribution to the auroral conductance are very large. Thus, here we follow the approach of Waters et al. (2004), and use SuperDARN to estimate the electric fields. Section 2 gives an overview of the event, observations used for the analysis, and the initial energy input distributions derived from the globally distributed data. Section 3 presents detailed comparison with DMSP in-situ observations and the corrections derived for the initial energy input estimates. The results and implications are discussed in Sect. 4 and summarized in Sect. 5.

\section{Data sets and event overview}

\subsection{Event description}

The interval 10 January 2002, 10:00-12:00 UT, was selected for study from a database of events with simultaneous broad coverage in SuperDARN radar returns and consistent distributions of magnetic perturbations over the Iridium constellation. The event occurred during northern winter and for southward IMF making it ideal for our purposes. Moreover, IMAGE FUV obtained excellent auroral images throughout the event. Observations of the particle precipitation and Poynting flux are available from two DMSP satellites, F13 and F15, which we use for independent validation of the global energy input distributions along the satellite tracks. Figure 1 shows the solar wind (McComas et al., 1998) and IMF conditions (Smith et al., 1998) observed by the Advanced Composition Explorer (ACE) spacecraft, located at the first Lagrangian point (L1). In this plot the ACE data have been time-shifted by the average advective delay from L1 to Earth implied by the solar wind speed. The interval studied here is marked by two vertical dashed lines. From top to bottom the panels show the IMF $B_{\mathrm{x}}, B_{\mathrm{y}}$ and $B_{\mathrm{Z}}$ components in GSM coordinates; the IMF magnitude, $B_{\mathrm{t}}$; the IMF clock angle defined by $\arctan \left(B_{\mathrm{y}} / B_{\mathrm{z}}\right)$; the proton number density, $n_{\mathrm{p}}$; the proton bulk speed, $v_{\mathrm{p}}$; and the proton dynamic pressure, $p_{\text {dyn }}$. The time averages and standard deviations for the IMF magnitude and its three GSM components are $B_{\mathrm{t}}=11.1 \pm 1.8 \mathrm{nT}, B_{\mathrm{x}}=-3.3 \pm 2.6 \mathrm{nT}$, $B_{\mathrm{y}}=5.6 \pm 3.6 \mathrm{nT}$, and $B_{\mathrm{z}}=-6.9 \pm 4.2 \mathrm{nT}$. This corresponds to an IMF clock angle of $129^{\circ} \pm 62^{\circ}$ with respect to the northward direction. The average solar wind proton number den- sity is $12.3 \mathrm{~cm}^{-3}$, and the mean solar wind flow speed is $419 \mathrm{~km} / \mathrm{s}$, giving an advective delay of $60 \mathrm{~min}$ from L1. The variability of IMF orientation is larger than that of the "stable IMF" criterion applied to the event selection process in previous studies with Iridium observations, where the maximum deviation of the IMF orientation from the average direction was required to be at most $\pm 25^{\circ}$ (Korth et al., 2004, 2005, 2008).

The Iridium observations for the interval are shown in Fig. 2. The figure shows the Iridium cross-track component of the magnetic perturbations (panel a) and their spherical harmonic vector fit (panel b). The perturbations are obviously dominated by the signatures of the large-scale Birkeland currents. Since the Iridium samples are collected over a two-hour period, and since the IMF orientation was somewhat variable, it is important to verify that the morphology of the magnetic perturbations is consistent over the sample interval so that the spherical harmonic fit faithfully represents the large-scale current system. Close examination of the observations in Fig. 2a shows that the Iridium data are generally self consistent, that is, different samples in close proximity are in the same direction and have similar magnitudes, so while some smaller-scale variations may be missed, the large-scale current structures should be reliable.

SuperDARN observations provide additional confidence in the stability of the ionospheric convection and associated Birkeland currents. Figure 3 shows six distributions of the ionospheric plasma vector velocity derived from SuperDARN line-of-sight Doppler shifts, color-coded according to their magnitude, each of which is derived from two minutes of data. The associated electric potential, represented by the contour lines in Fig. 3, corresponds to a two-cell large-scale circulation of plasma in the ionosphere. The convection pattern is dominated by the dawn convection cell and is fairly stable in its overall configuration.

Observations of the far-ultraviolet aurora by IMAGE FUV/WIC (Fig. 4) demonstrate a persistent auroral morphology during the interval of interest. The auroral snapshots, shown at ten minute intervals, bear no indications of major substorm activity, consistent with the quick look $\mathrm{AE}$ index that was $<300 \mathrm{nT}$ during this period. The WIC images show multiple arc structures in the pre-midnight region which correspond to magnetic signatures evident in the Iridium observations between $60^{\circ}$ and $70^{\circ}$ MLAT near 21:00 MLT. In the pre-midnight sector the magnetic perturbations display two maxima indicating an additional set of Birkeland currents associated with the double auroral structure. This meso-scale structure in the currents is not resolved in the spherical harmonic fit which uses a comparatively coarse latitude resolution to accommodate the relative sparsity of the Iridium sampling data elsewhere. 


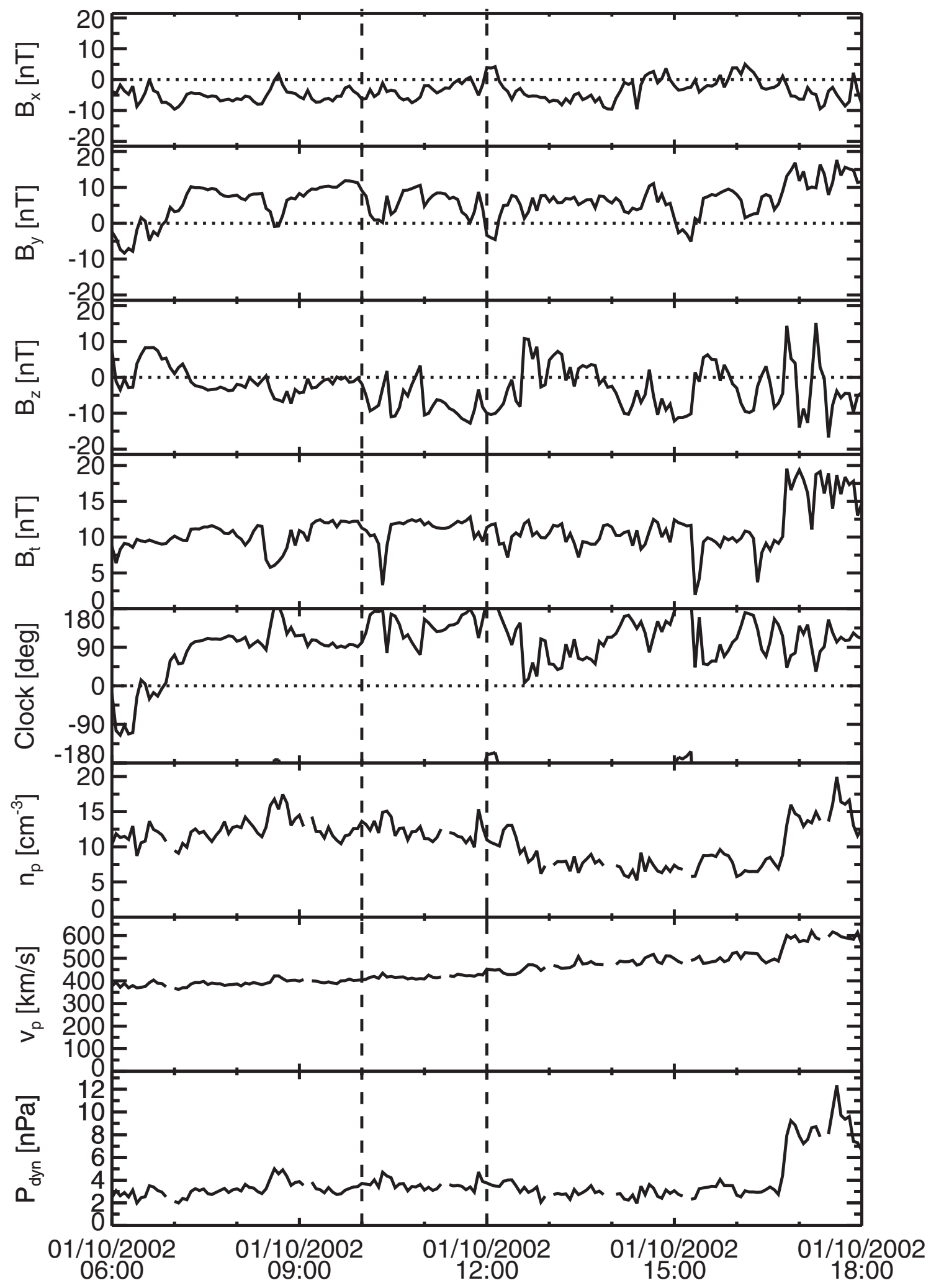

Fig. 1. ACE solar wind and IMF conditions on 10 January 2002 in GSM coordinates time-shifted to Earth. The interval of this study is marked by vertical dashed lines. See text for details. 


\section{January 2002, 10:00 - 12:00 UT (North)}
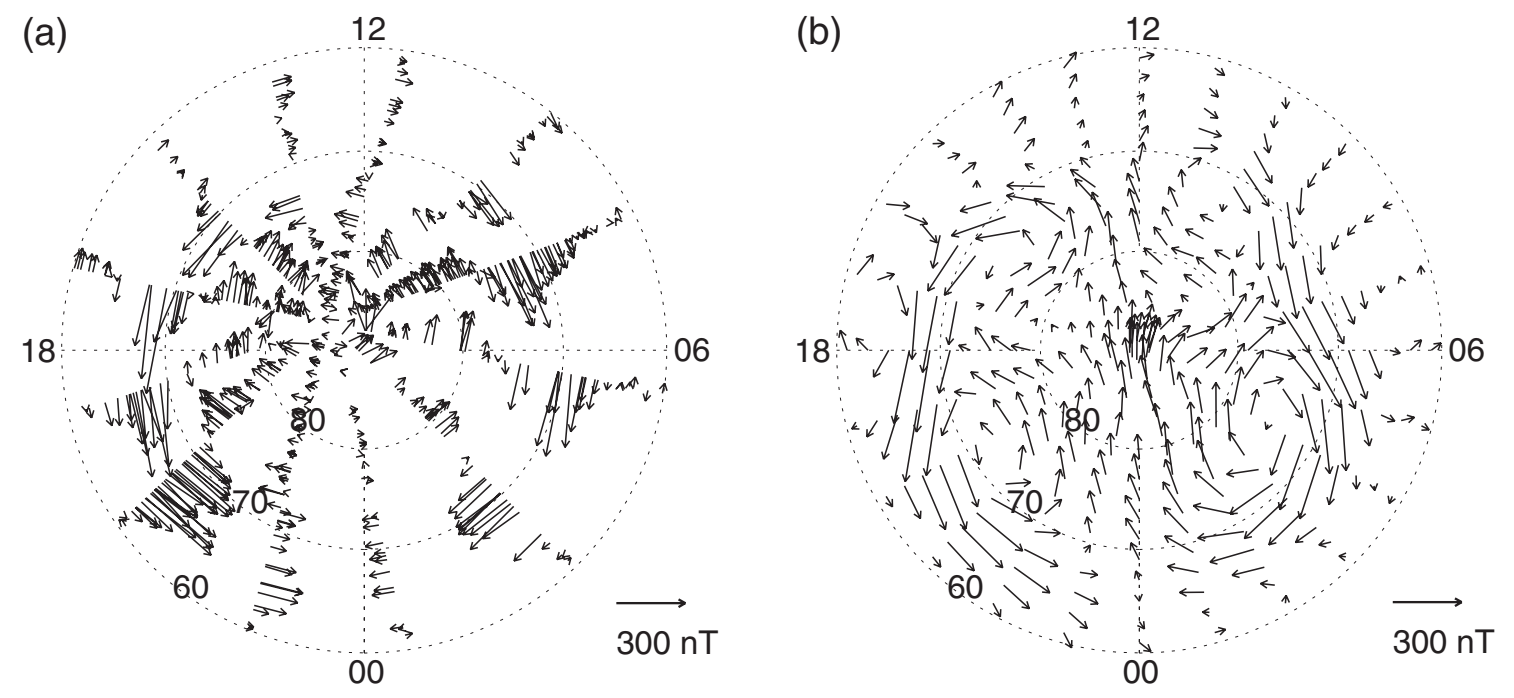

Fig. 2. Iridium observations on 10 January 2002, 10:00-12:00 UT: (a) Iridium cross-track magnetic perturbations, (b) spherical harmonic vector fit of the magnetic field, $\boldsymbol{b}$.

\subsection{Global EM flux estimation}

To estimate the global EM flux distribution, we follow Waters et al. (2004) and calculate the radial component of the Poynting vector, $S_{\mathrm{r}}$, from distributed fits of the magnetic perturbations, $\boldsymbol{b}$, recorded by the Iridium constellation and the ionospheric electric field, $\boldsymbol{E}$, from SuperDARN radar scatter using

$S_{\mathrm{r}}=\frac{1}{\mu_{0}}(\boldsymbol{E} \times \boldsymbol{b})_{\mathrm{r}}$.

At high latitudes the magnetic field is nearly radial so we define the parallel Poynting vector as $\boldsymbol{S}_{\|}=S_{\mathrm{r}} \hat{\boldsymbol{r}}$, where $\hat{\boldsymbol{r}}$ is the radial unit vector. The use of Eq. (1) assumes that the conditions at the ionosphere are approximately time stationary.

The global electric field distribution was calculated as follows. The SuperDARN observations acquired with a twominute cadence were used to determine a spherical harmonic representation of the ionospheric flow velocities, $\boldsymbol{v}$, for each two minute interval. In regions with no radar returns, a statistical model constrained the fit. Using a model magnetic field, $\boldsymbol{B}_{0}$, the electric fields were calculated from the plasma velocities as $\boldsymbol{E}=-\boldsymbol{v} \times \boldsymbol{B}_{0}$. The average electric field for the interval was then calculated by averaging the northward and eastward components separately at each grid point over all of the patterns acquired during the two-hour period. Equivalent flows are obtained by rotating the electric field vectors counter-clockwise by $90^{\circ}$ to show the corresponding flows. The average equivalent flow distribution is shown in Fig. 5a.

The distribution of the EM energy flux computed from the SuperDARN electric field and the Iridium magnetic pertur-

bations (Fig. 5a and b) is shown in Fig. 5c, where the energy flux is positive downward and regions without radar returns are gray-shaded. EM energy deposition is evident at nearly all local times in a $5^{\circ}-10^{\circ}$ wide annulus centered near $70^{\circ}$ MLAT. Within this annulus, the distribution of $\boldsymbol{S}_{\|}$shows peaks at dawn $\left(9 \mathrm{~mW} / \mathrm{m}^{2}\right)$ and dusk $\left(6 \mathrm{~mW} / \mathrm{m}^{2}\right)$, where the magnetic perturbations are largest and are oriented nearly perpendicular to the electric field. The total EM power integrated over the annulus is $34 \mathrm{GW}$. Furthermore, the EM energy deposition appears elevated over nearly the entire polar cap region. Upward directed $\boldsymbol{S}_{\|}$of small magnitudes are observed in several regions, all of which are close to minima in $\boldsymbol{E}$ or $\boldsymbol{b}$, or both. Relatively small errors in the baselines would change the locations and intensities of these upward EM flux regions. We therefore do not regard these results as providing evidence for upward EM flux above the observational uncertainties. The total EM power integrated over the Northern Hemisphere region poleward of $60^{\circ}$ MLAT is $47 \mathrm{GW}$. This estimate includes the region near the geomagnetic poles, where the SuperDARN coverage is sparse, and the magnitudes of the Poynting vector determined in this region may be less reliable. However, the contribution to the total EM power at latitudes $>80^{\circ}$ MLAT is only about $5 \mathrm{GW}$, or $10 \%$, so that uncertainties arising from including the pole region in our estimate are small compared to the overall uncertainties associated with our analysis discussed below.

\subsection{Particle energy flux estimation}

Auroral emissions observed in multiple UV bands can be used to infer energy deposition due to precipitating particles. 


\section{January 2002, 10:00 - 12:00 UT}
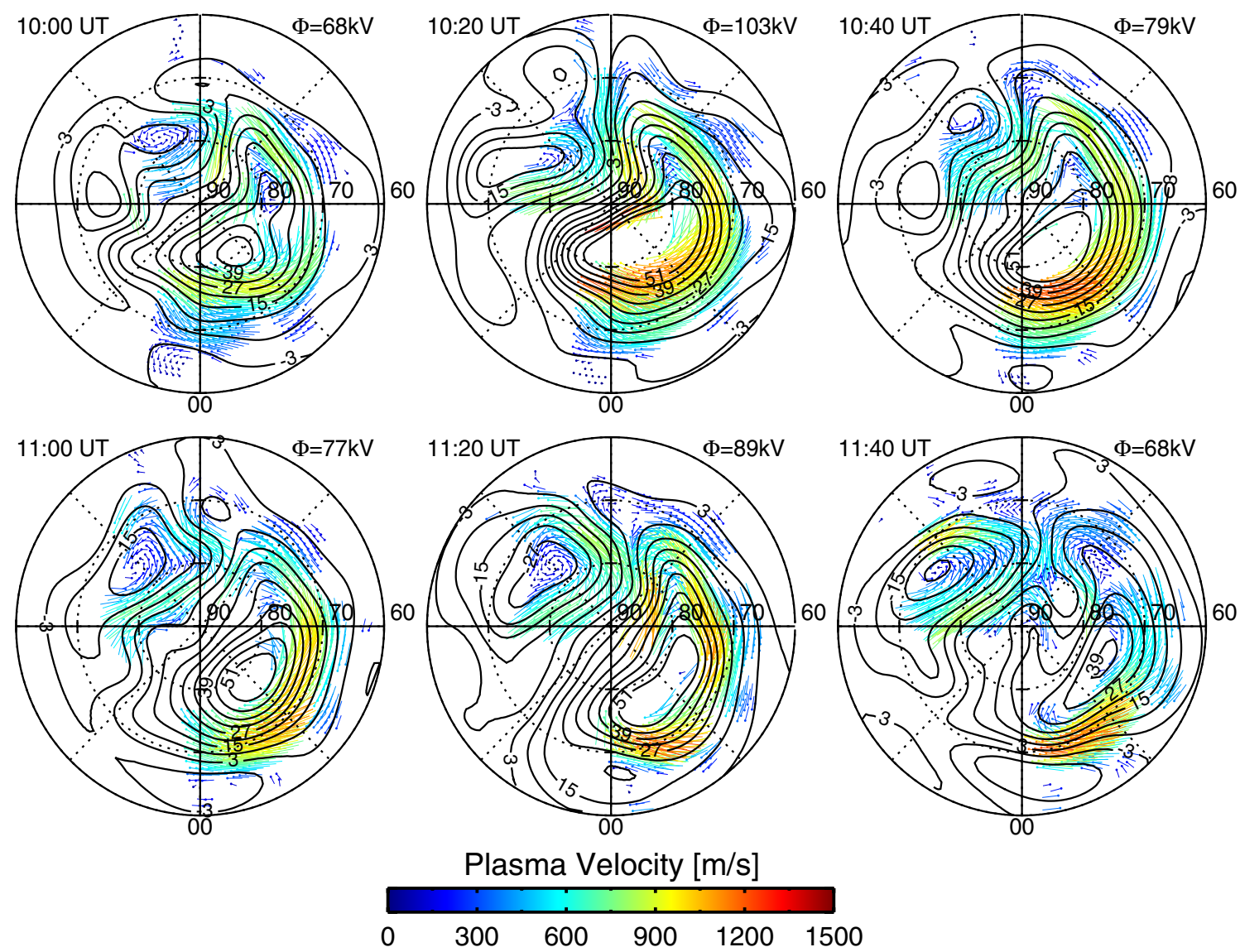

Fig. 3. SuperDARN maps of ionospheric plasma velocities and electric potential on 10 January 2002 between 10:00 UT and 12:00 UT for six intervals with 2-min data accumulation each.

As seen in Fig. 4, IMAGE FUV had excellent viewing of the Northern Hemisphere ionosphere for the event. The FUV instrument consists of a Wide-Band Imaging Camera (WIC) and a dual-wavelength Spectrographic Imager (SI). The WIC provides broad-band UV images of the aurora by imaging the nitrogen lines and bands between 140 and $180 \mathrm{~nm}$ wavelength. The dual-channel SI images both Doppler-shifted Ly- $\alpha$ emissions, produced by precipitating protons, and OI $135.6 \mathrm{~nm}$ emissions in the SI-12 and SI-13 channels, respectively. The technique to estimate the particle energy flux from the multi-wavelength auroral images is described in detail by Frey et al. (2003). In brief, we first estimate the precipitating proton energy flux from the luminosities in the Ly- $\alpha$ band and a model prediction for the proton mean energy (Hardy et al., 1989, 1991). We then subtract the proton contribution from the WIC and SI-13 images, leaving an estimate for the signal from electron precipitation. Comparison of the WIC and SI-13 signals provides a measure of the electron mean energy, which can then be used to determine the electron energy flux. These estimates are typically accurate to within a factor of two (Frey et al., 2003). The total particle precipitation energy flux is the sum of the proton and electron contributions. The robustness of this technique has been tested by comparison with in-situ observations of the electron energy flux by the FAST satellite (Frey et al., 2001, 2003).

The IMAGE FUV particle inputs were processed for comparison with the EM energy flux by re-registering the twominute resolution IMAGE FUV flux results in magnetic coordinates and averaging over the same interval used for the EM energy flux analysis. All particle energy flux distributions obtained during the two-hour period were averaged by sorting each distribution into bins according to magnetic latitude and local time and calculating the average within each bin. Figure 6 shows from left to right the average (a) electron, (b) proton, and (c) total particle energy flux for the interval 10 January 2002, 10:00-12:00 UT. The electron precipitation (Fig. 6a) occurred in a $5^{\circ}-10^{\circ}$ wide latitude band at all local times except within a small region near local noon. On the duskside, the electron energy flux peaks near $70^{\circ}$ MLAT, 


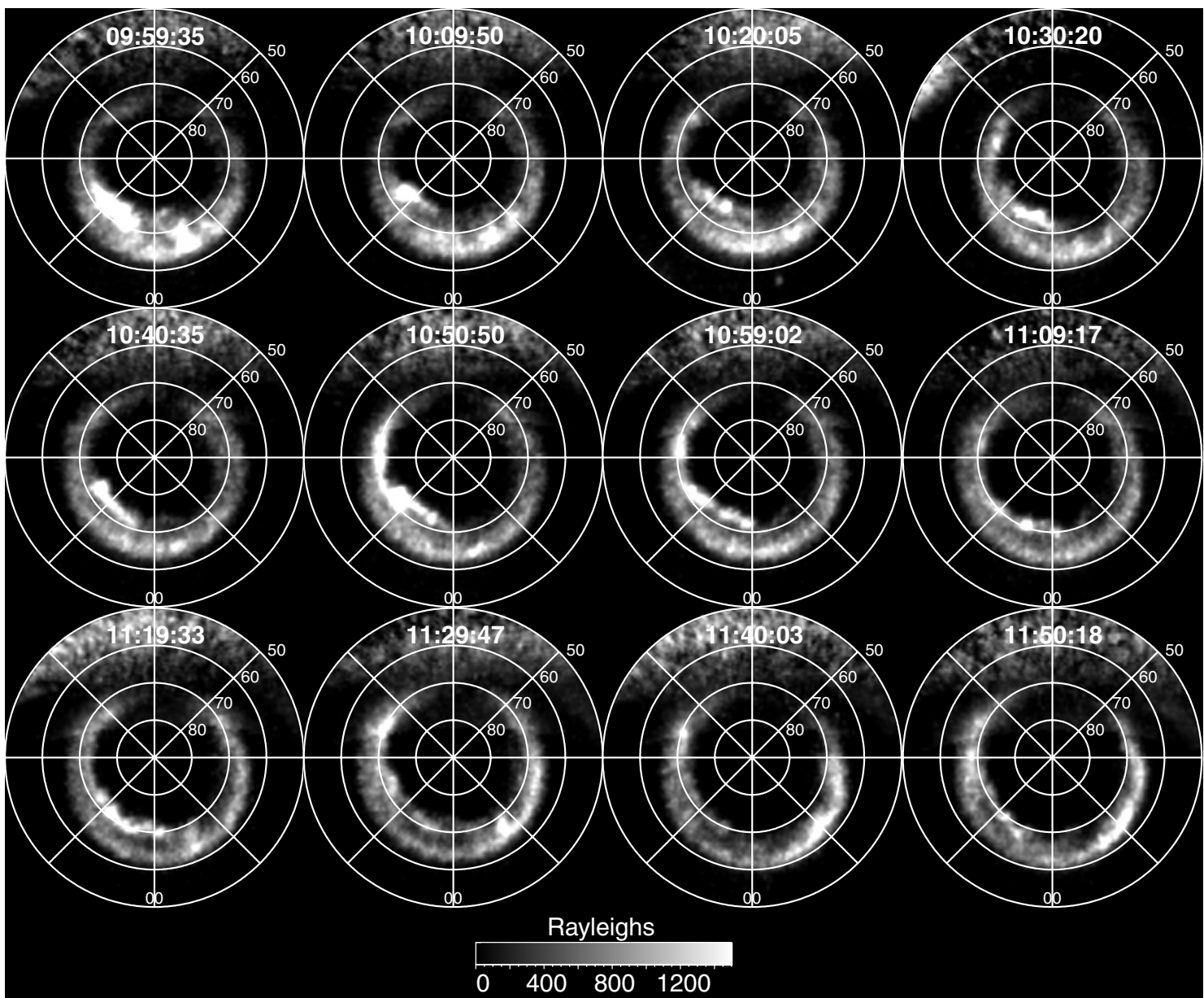

Fig. 4. IMAGE FUV/WIC auroral emissions on 10 January 2002, 10:00-12:00 UT.

\section{January 2002, 10:00 - 12:00 UT}

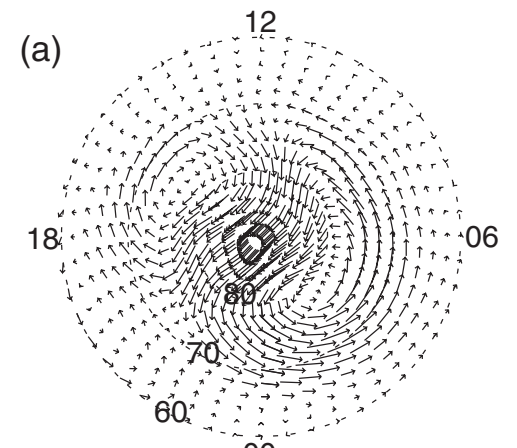

00

Electric Field

Rotated CCW $90^{\circ}$

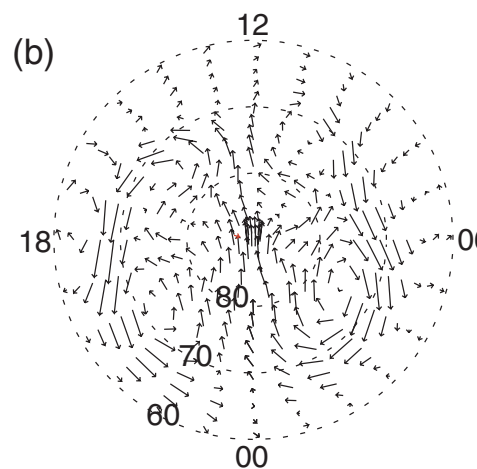

Magnetic Field

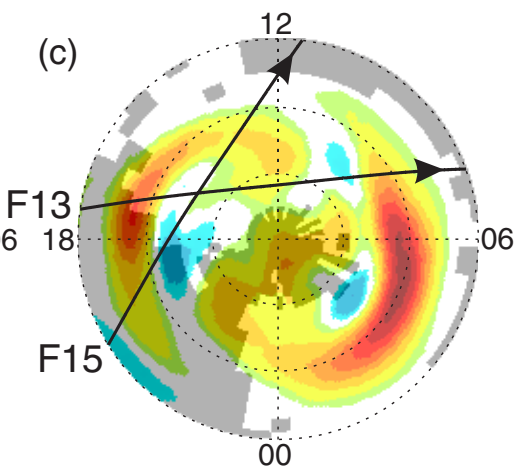

Poynting Flux $\left[\mathrm{mW} / \mathrm{m}^{2}\right]$

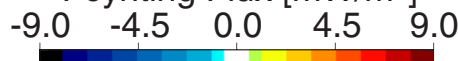

Fig. 5. The global distribution of the electromagnetic energy flux (panel c) on 10 January 2002, 10:00-12:00 UT, calculated from the average SuperDARN electric field (panel a) and the spherical harmonic fit of the Iridium magnetic perturbations (panel b, same as Fig. 2b). Regions without SuperDARN returns are gray-shaded in panel (c). 


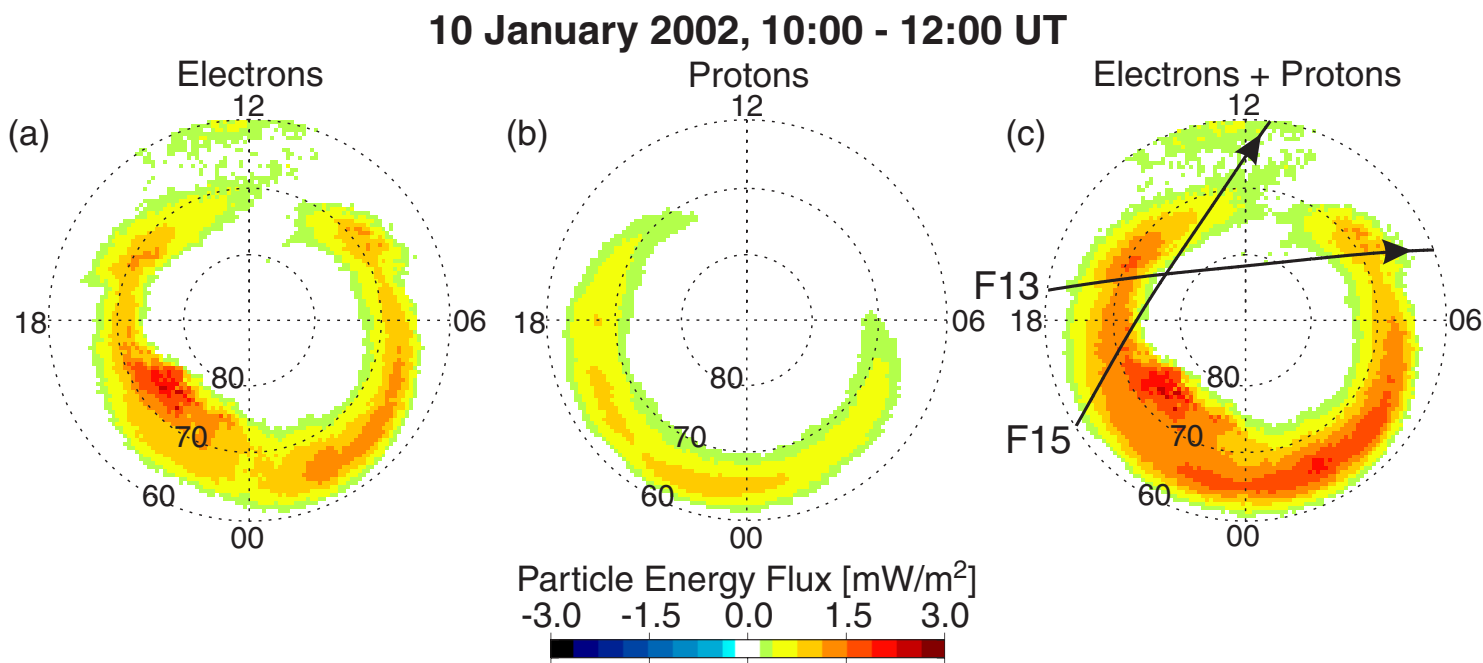

Fig. 6. The global distribution of the average (a) electron, (b) proton, and (c) total particle energy flux on 10 January 2002, 10:00-12:00 UT, calculated from IMAGE FUV auroral emissions.

whereas at dawn the maximum is observed approximately $5^{\circ}$ further toward the equator relative to dusk. The maximum electron energy flux is $2.4 \mathrm{~mW} / \mathrm{m}^{2}$ and is in the pre-midnight region. The proton precipitation flux (Fig. 6b) is mostly on the nightside and extends from post-midnight through the evening sector into the late afternoon sector. The proton energy flux maximizes in the pre-midnight sector about $5^{\circ}$ equatorward of the electron precipitation. The total hemispheric power due to particle precipitation integrated poleward of $60^{\circ}$ MLAT from Fig. $6 \mathrm{c}$ is $19 \mathrm{GW}$, with contributions from electrons and protons amounting to $13 \mathrm{GW}$ and $6 \mathrm{GW}$, respectively.

\section{Comparison with DMSP observations}

Both the particle and EM energy input estimates above are subject to uncertainties so it is essential to independently evaluate the results. The EM energy flux is computed from distributed fits of magnetic perturbations and electric fields. Obviously, the spherical harmonic fit cannot resolve features smaller than the shortest wavelength basis function. Fluctuations on spatial scales $<4^{\circ}$ are not represented by these fits. Thus we need to estimate the fraction of the total power resolved by the maps. In addition, the native resolution of the input magnetic field or radar data may not be high enough to capture the actual extrema in the magnetic or electric field signatures. By comparison of in-situ observations of the magnetic perturbations by Ørsted and DMSP with Iridium fits evaluated along the satellite orbit, it was found that the maximum magnetic perturbations are underestimated by the fit, commonly by $30 \%-50 \%$ (Korth et al., 2004, 2005). Statistical comparison of SuperDARN line-of-sight velocities with DMSP drift meter observations by Drayton et al.
(2005) showed that the SuperDARN velocities tend to be somewhat smaller then concurrent DMSP ion drifts, especially for larger electric fields. Finally, the IMAGE FUVderived particle flux input relies on a number of assumptions. For example, the proton energies are estimated from statistical models. We therefore checked results for each parameter against in-situ observations from DMSP satellites.

\subsection{EM energy flux}

The DMSP satellites carry instrumentation from which both particle and EM energy flux can be calculated along the DMSP track. The trajectories of DMSP F13 and F15 used in this study are shown in Figs. 5 and 6. Figure 7 compares the DMSP F13 (left panel) and F15 (right panel) observations of the eastward component of the magnetic perturbations (top panel) and the northward electric field component (middle panel), with the spherical harmonic fit results evaluated along the respective satellite trajectory. The 1-s resolution magnetometer data and 4-s resolution drift meter data from DMSP are shown as solid black lines, and the corresponding evaluations of the Iridium and SuperDARN spherical harmonic fits are represented by dashed black lines. While we compare both the northward (N) and eastward (E) components of $\boldsymbol{E}$ and $\boldsymbol{b}$ in our analysis, we display just $E_{\mathrm{N}}$ and $b_{\mathrm{E}}$ since their product gives the dominant contribution to $S_{\|}$. The parallel Poynting vector, evaluated from the complete horizontal DMSP fields, positive downward, is shown in the bottom panel. Comparison of the DMSP F13 data with the fit evaluations shows that the location of the maxima in both the magnetic perturbations and the electric field at dawn and dusk agree within the latitude resolution of the fits. However, the peak magnitudes in both the magnetic perturbations and the 

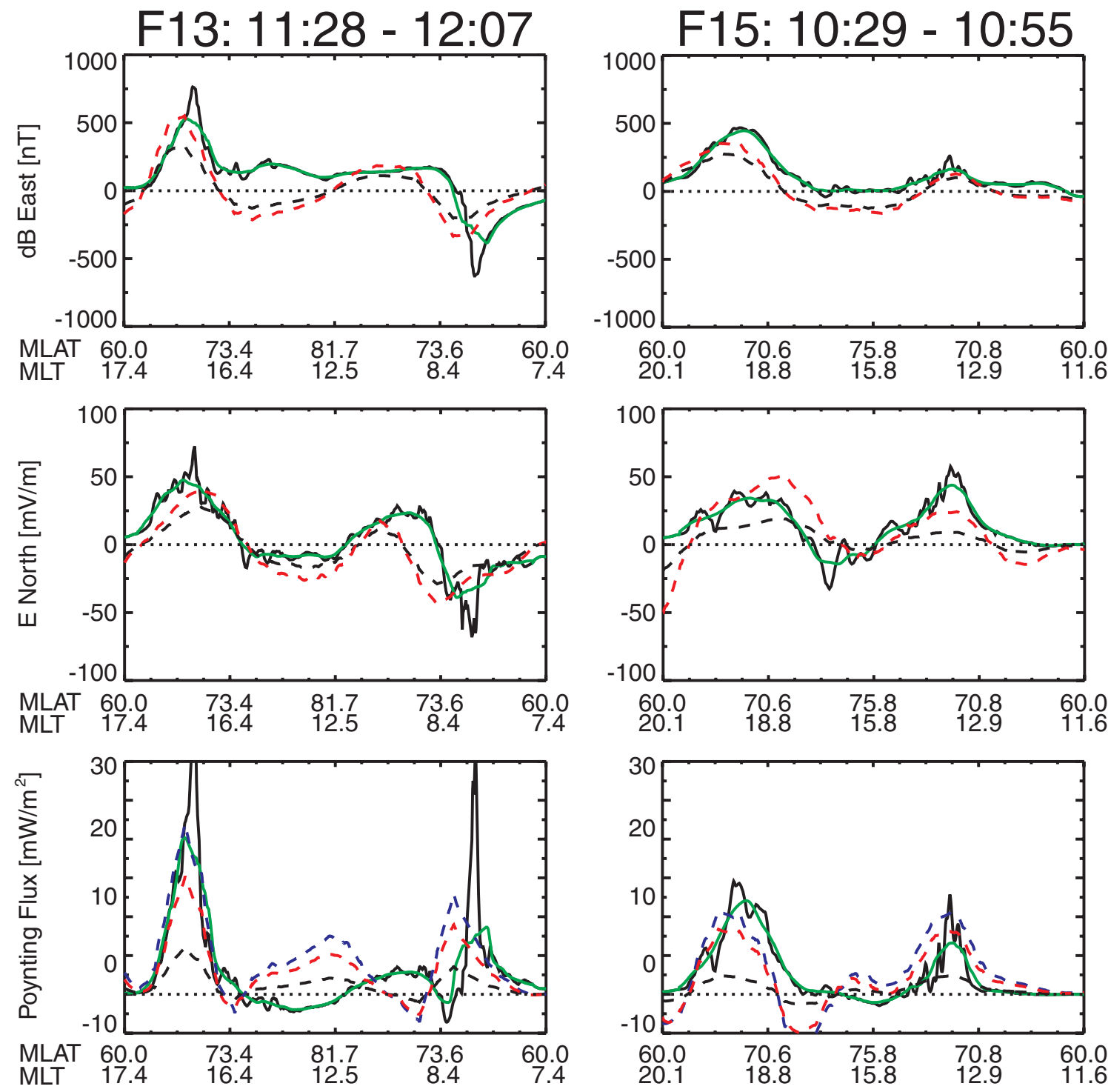

Fig. 7. Comparison of eastward magnetic perturbation, northward electric field, and Poynting flux from the Iridium/SuperDARN fits (dashed black lines) with DMSP F13 (left panel) and F15 (right panel) data having 1-s (solid black lines) and 70-s averaged (green lines) resolution. The dashed red lines represent the scaled components $b_{\mathrm{E}}$ and $E_{\mathrm{N}}$ and the Poynting flux computed therefrom. The dashed blue lines result from applying the scaling directly to the Iridium/SuperDARN Poynting flux computations.

electric fields obtained from the fits are significantly lower than those observed by DMSP.

To determine how much of the underestimation in the fits is due to the coarse spatial resolution of the fits and how much is due to a true underestimation of the large-scale fields, one needs to evaluate contributions of long and short length-scales to the DMSP results. To illustrate this qualitatively, the green line shows a 70-s running average of the DMSP data, commensurate with the $4^{\circ}$ latitude resolution of the Iridium and SuperDARN fits. The peak magnitudes of the boxcar-averaged magnetic perturbations and electric fields from DMSP are significantly lower than the observed maxima, but are still a factor of $\sim 2$ larger than those evaluated from the Iridium and SuperDARN fits. Consequently, the peak magnitude of the parallel Poynting vector from Iridium and SuperDARN is only about one-fourth of the corresponding large-scale energy flux observed by F13. The DMSP F15 comparison gives similar results for the magnetic perturbations, reproducing maxima at both dusk and noon with a somewhat lower magnitude. The SuperDARN electric field is much smaller in magnitude than that measured by DMSP F15, especially near noon where the latter exceeds the former by a factor of $\sim 5$. This comparison is made more rigorously below by comparing the global estimates with the 

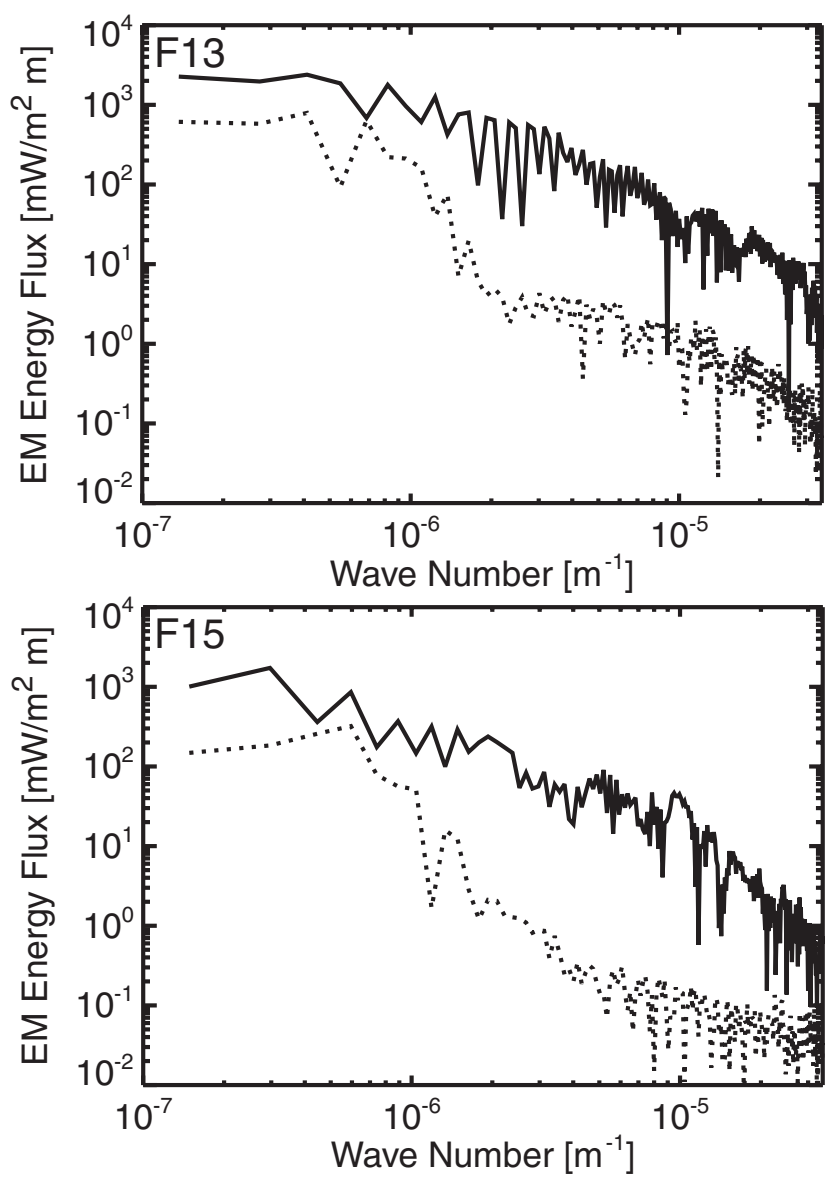

Fig. 8. Power spectra of DMSP (solid line) and Iridium/SuperDARN (dotted line) electromagnetic energy flux.

DMSP data via spectral analysis to compare only the range of wavelengths resolved in the global estimates.

Analyzing the DMSP and Iridium/SuperDARN results in the frequency or wave number domain allows us both to derive correction factors to scale the large-scale Iridium/SuperDARN results and to determine how much EM power is present at shorter scales but missed in the global estimates. First, we evaluate the magnetic perturbations and the electric fields along the DMSP track from the spherical harmonic fits and calculate the parallel Poynting vector using Eq. (1). The time series of $\boldsymbol{E}, \boldsymbol{b}$, and $S_{\|}$are then decomposed into their spectral components using Fast Fourier Transform (FFT) analysis to yield wave number power spectra. Figure 8 shows the power spectra for the parallel Poynting vector from DMSP F13 and F15 (solid line) and those obtained from the corresponding Iridium and SuperDARN fits (dotted line). The Nyquist wave number for the DMSP results is approximately $1.5 \times 10^{-5} \mathrm{~m}^{-1}$, corresponding to 4$\mathrm{s}$ drift meter sampling. For both F13 and F15, the DMSP data yield power-law spectra while the spectra of the Iridium/SuperDARN fits have a sharp decrease in power at ap- proximately $10^{-6} \mathrm{~m}^{-1}$ wave number at the ionosphere, corresponding to a wave length in degrees of $\sim 8^{\circ}$. This fall off in power reflects the half-wave-length resolution of both the Iridium and SuperDARN spherical harmonic fits.

These power spectra are used to measure the degree of underestimation of the large-scale energy flux in the Iridium/SuperDARN results. We take the ratio of the integrals of the spectral densities from DMSP, $P_{\mathrm{DMSP}}$, and Iridium/SuperDARN, $P_{\mathrm{IrSD}}$, over the long wavelength range:

$$
c=\frac{\int_{0}^{v_{\max }} P_{\mathrm{DMSP}}(v) \mathrm{d} v}{\int_{0}^{v_{\max }} P_{\mathrm{IrSD}}(v) \mathrm{d} v},
$$

where $v_{\max }$ is the cutoff wave number. Applying Eq. (2) to the power spectra in Fig. 8, we find scale factors of $c=3.6$ and $c=4.4$ for the DMSP F13 and F15 passes, respectively. The dashed blue lines in the bottom panels of Fig. 7 represent the EM energy flux from Iridium and SuperDARN multiplied by the above scale factors. In the regions, where the EM energy flux deposition maximizes, the peak magnitudes of the scaled Poynting vector are found to be in good agreement with the DMSP observations with running average (green line in Fig. 7). The integral power of the scaled EM energy flux obtained from the Iridium and SuperDARN fits matches that measured by DMSP on spatial scales larger than $4^{\circ}$ to within $4 \%$ and $6 \%$ along the F13 and F15 passes, respectively. Applying an average scale factor of $c=4.0$ globally, we obtain a hemispheric power of $188 \mathrm{GW}$ for our best estimate of the total EM energy deposition.

We also use power spectral analysis to determine the relative underestimation of $\boldsymbol{E}$ and $\boldsymbol{b}$ in the global estimates by applying Eq. (2) separately to the magnetic perturbations and the electric fields. Along the F13 trajectory, we find a scale factor of 1.6 for both the magnetic perturbations and the electric field, while, along the F15 orbit, we obtain scale factors of 1.2 and 2.8 for $b_{\mathrm{E}}$ and $E_{\mathrm{N}}$, respectively. The scaled magnetic perturbations and electric fields and the parallel Poynting vector are shown as dashed red lines in Fig. 7. Comparison of DMSP and SuperDARN electric fields along the F15 orbit shows that the largest discrepancies in the electric field magnitude exist on the dayside where many radar returns are obtained, so the underestimate cannot be simply attributed to low observational coverage. Although the convection pattern is stable in its overall configuration, some temporal variability of the plasma velocities does exist in the SuperDARN maps along the dayside pass of the F15 orbit near the convection "throat". This may lead to increased departure of the averaged electric field from the in-situ observations.

The spectral analysis also provides information on the energy flux deposited in smaller scales than resolved by the Iridium/SuperDARN technique. To estimate this quantitatively we integrate the DMSP energy flux spectra separately for wave numbers smaller and larger than $v_{\max }$ and compare 
these integrals to the total energy flux. Along the F13 orbit $82 \%$ of the energy flux is attributed to spatial scales associated with wave numbers $\leq v_{\max }$. For the F15 pass, the long wavelength range captures $94 \%$ of the power. These results indicate that the energy content of the small-scale structures is less than $20 \%$ of the total, demonstrating that the distributed fits used in our analysis provide a suitable tool for studying both the location and magnitude of the EM energy deposition on a global scale.

\subsection{Particle energy flux}

The DMSP observations can also be used to check the particle energy flux estimates derived from auroral imaging by comparing the particle energy flux distribution from IMAGE FUV (Fig. 6c) with measurements by the SSJ/4 particle detector (Hardy et al., 1984). Although the low energy ion detectors on both DMSP spacecraft, F13 and F15, are known to be degraded, the decreased sensitivity in the energy range below $1 \mathrm{keV}$ is expected to have only small impact on the calculation of the total particle energy flux. On a global scale the ion contribution to the total particle energy flux is much smaller than that of the electrons, typically no more than 20\% (Gérard et al., 2001; Hubert et al., 2002). In addition, the energy range affected by the degradation does not contribute significantly to the ion energy flux in the proton aurora, where the characteristic ion energy is a factor of five or more greater (Newell et al., 2005) than the highest energy of a degraded channel. The DMSP observations should therefore reasonably reflect the particle energy deposition of the natural system.

Figure 9 shows from top to bottom the total particle, proton, and electron energy flux observed by DMSP (black) F13 (left) and F15 (right) together with respective quantities evaluated from IMAGE FUV auroral emissions (red), registered at the time and location of the DMSP observations. That is, the FUV image-derived flux is not taken from a single average image but from the pixel closest to the DMSP location and from the image closest in time to each DMSP particle data measurement. The particle energy flux along the DMSP F13 orbit peaks at dawn and dusk associated with the precipitation into the auroral oval. At dusk, the latitude at which the peak in the precipitation is observed corresponds well with that inferred from the auroral images. Here, the peak energy flux observed by DMSP exceeds that inferred from the FUV data by a factor of $\sim 1.5$. Comparison of the proton and electron energy flux shows that the electrons provide the dominant contribution to the total particle flux and that the underestimate of the electron energy flux is the cause for the difference in the peak amplitude. At dawn, the discrepancy between the DMSP and IMAGE FUV peak flux is about twice as large. The larger difference on the dawnside is due to the fact that in this region the DMSP F13 track is located sunward of the terminator so that uncertainties associated with the dayglow correction lead to less reliable de- terminations of the electron energies and hence the electron energy flux. Along the DMSP F15 orbit, a peak in the total particle energy flux is measured in the pre-midnight sector near $70^{\circ}$ MLAT. A peak of similar magnitude is also evident in the auroral data, where, however, it is observed about $5^{\circ}$ equatorward.

The proportions of electron and proton energy flux measured by the two platforms are significantly different. The F15 particle data indicate a total particle flux consisting largely of electrons with only small contributions from protons. On the other hand, the auroral imaging data show a total particle flux that is comprised nearly equally of contributions from electrons and protons. While the electron precipitation is observed at approximately the same latitudes by F15 and IMAGE FUV, the FUV-derived proton flux extends further equatorward and shows a peak magnitude about four times larger than observed by F15. During the latter half of the orbit, the F15 position magnetically maps to the dayside ionosphere, where, similar to the F13 orbit, the electron flux inferred from auroral data deviates in some locations significantly from the DMSP particle data. The multiple peak structure evident in the IMAGE FUV data is not observed by F15. The IMAGE FUV technique relies on the ratio of counts measured in the WIC and SI13 channels, whereby the count rates in the SI13 channel are generally only between 20 and 50 counts in the aurora. A lower-end cutoff of 5 counts is imposed on the SI13 channel, below which no attempt is made to calculate the mean electron energy. The scattered dropouts in the mean energy calculation adversely effect the conversion of the WIC auroral luminosity to energy flux and are the cause of the spurious peaks.

The DMSP particle observations can be used to derive suitable scale factors for the particle flux estimates inferred from the auroral emissions. We calculate the scale factors separately for electrons and protons from the ratios of the integrated energy fluxes obtained from DMSP and IMAGE FUV. Owing to uncertainties in the dayglow correction discussed above, the electron energy flux estimates are less accurate on the dayside than they are on the nightside. We therefore restrict the analysis of the particle flux scale factor to the nightside. The energy flux ratios from DMSP and IMAGE FUV for electrons and protons are 1.12 and 0.58 for F13 and 1.61 and 0.17 for F15. From the above ratios we obtain average scale factors of 1.37 and 0.38 for the electron and proton energy flux, respectively. Applying these scale factors to the electron $(13 \mathrm{GW})$ and proton $(6 \mathrm{GW})$ energy deposition found above, the corrected energy deposition for these species are $17.8 \mathrm{GW}$ and $2.3 \mathrm{GW}$, respectively, yielding a corrected total particle input of about $20 \mathrm{GW}$.

\section{Discussion}

The distribution of EM energy flux is qualitatively consistent with previous global estimates for southward IMF 

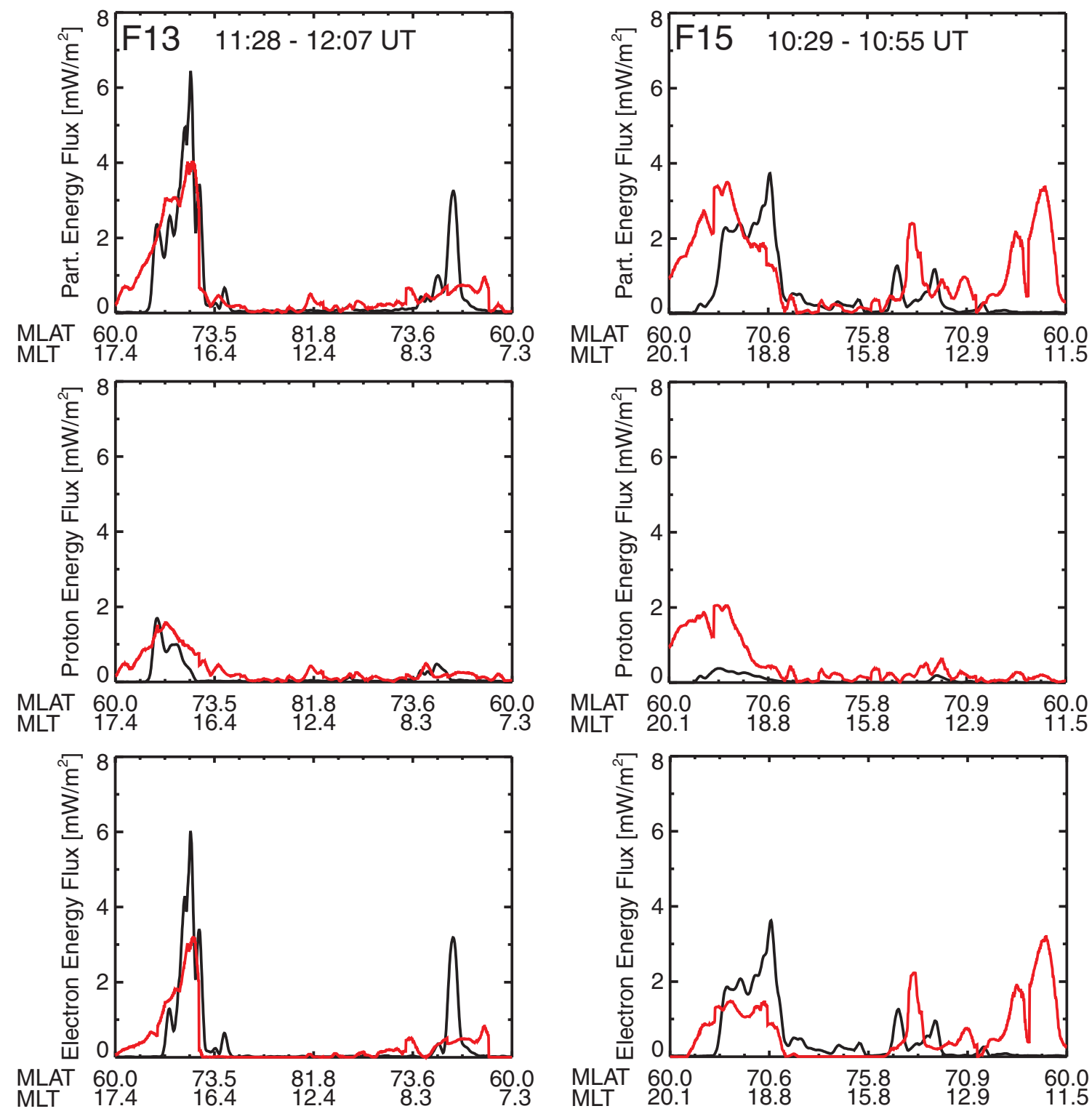

Fig. 9. Comparison of DMSP F13 (left panel) and F15 (right panel) particle energy flux estimates (black) with IMAGE FUV calculations (red) along the satellite orbits. The top, middle, and bottom panels show the total particle, proton, and electron energy flux, respectively.

(e.g. Waters et al., 2004). The global mapping of the parallel Poynting vector in Fig. 5 shows that the transport of EM energy to the ionosphere occurs over a large fraction of the high-latitude ionosphere. Most of the EM energy flux, about $72 \%$, is deposited in a $5^{\circ}-10^{\circ}$ wide annulus centered near $70^{\circ}$ MLAT, coinciding with the locations where the magnitudes of the magnetic perturbations and the electric fields are largest. In addition, there is a broad region of flux incident over the polar cap at higher latitudes. Within the auroral zone annulus, the energy deposition maximizes pre-dawn and predusk, where the electric field and the magnetic perturbations are not only largest but also nearly perpendicular, and de- creases toward local noon and midnight, where the magnetic perturbations assume smaller magnitudes. The Poynting vector from Iridium and SuperDARN observations was compared to in-situ observations by two DMSP satellites and the locations of enhanced energy flux were found to be in good agreement.

In the pre-midnight region, the Iridium constellation measures large eastward magnetic perturbations, yet the magnitudes of the associated Poynting vectors are small. This is caused by the absence of SuperDARN radar returns in this region where the missing observations are padded with pseudo-data from a statistical fit, which often inadequately 
represents the natural system. Thus, the Poynting vector in the lower-latitude pre-midnight region is probably underestimated. Figure 5c also shows modest EM energy deposition in the polar ionosphere, which amounts to about $10 \%$ of the total EM power. However, due to the sparseness of radar observations in the region near the geomagnetic pole, the SuperDARN electric field is least reliable in this region. In addition, the Iridium fitted magnetic perturbations in the polar cap deviate significantly from the observations and fall largely below the $2 \sigma$ confidence level, defined by Korth et al. (2004). Therefore, the EM energy deposition in this region is less reliably determined than elsewhere. Similarly, we have low confidence in the upward Poynting fluxes since most of the upward directed Poynting vectors are observed in or near areas where SuperDARN radar returns were unavailable. Also the magnitudes of the EM energy flux leaving the ionosphere are small compared to the error margins associated with the technique. We emphasize that we are not arguing that energy transfer from the I-T system to the magnetosphere does not occur, but rather that our technique does not reliably resolve such transfers.

Precipitating electrons and ions contribute to the particle precipitation energy flux in different regions. While the precipitation of both species is observed in a $5^{\circ}-10^{\circ}$ wide latitude band within the auroral oval, the electron and ion precipitation regions are spatially distinct (cf. Fig. 6). The electron precipitation is observed at all local times except within about $2 \mathrm{~h}$ of local noon, but occurs on the duskside at latitudes approximately $5^{\circ}$ further poleward than observed at dawn. The reason for the latitude difference is that the electron precipitation is tightly controlled by the Birkeland currents coupling the ionosphere to the magnetosphere. The Birkeland currents can be derived from the Iridium magnetic perturbations using the Curl-B approach described by Waters et al. (2001). The distribution of the large-scale Birkeland currents obtained in this manner is shown in Fig. 10 where upward field-aligned currents are shown in red and downward currents in blue. Regions were the Birkeland current density is below the $2 \sigma$ confidence level (Korth et al., 2004) are gray-shaded. The Birkeland currents resemble the Region 1/Region 2 current system documented statistically by Iijima and Potemra $(1976,1978)$. Overlaid on the Birkeland currents are the contours of the electron energy flux observed by IMAGE FUV (Fig. 6a) showing that the electron energy flux precipitates in the regions of upward field-aligned current at both dawn and dusk. Since precipitating energetic electrons give rise to discrete auroral arcs, our observations are consistent with previous observations of upward fieldaligned currents in regions of discrete aurora by Kamide and Akasofu (1976); Kamide et al. (1979). Furthermore, they are consonant with works by other authors suggesting that the upward Birkeland currents are carried at least in part by precipitating electrons (Arnoldy, 1974; Evans et al., 1977; Guo et al., 1999).

\section{January 2002, 10:00 - 12:00 UT (North)}
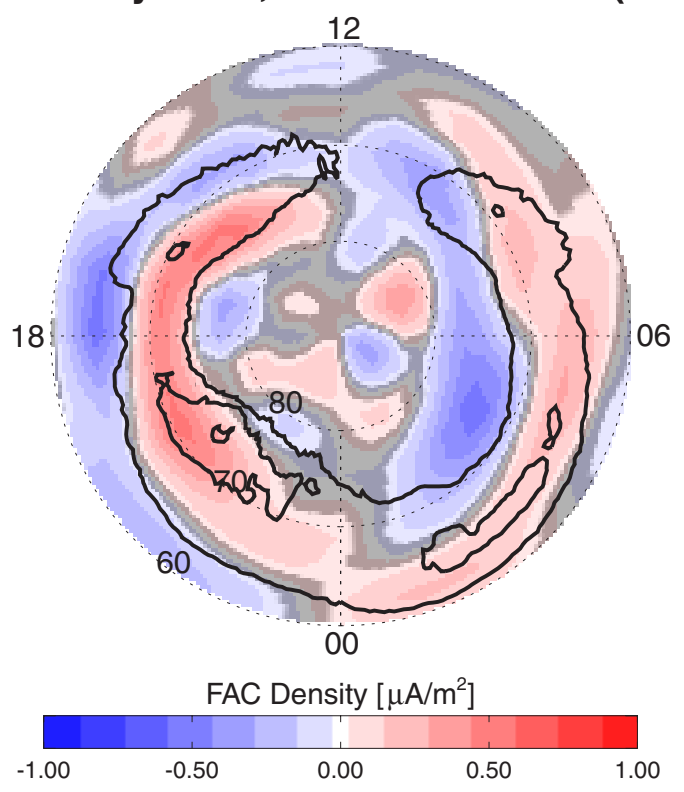

Fig. 10. Iridium Birkeland currents 10 January 2002, 10:0012:00 UT, with IMAGE FUV electron energy flux contours.

The ion energy fluxes are not as tightly linked to the Birkeland currents. The ion fluxes (Fig. 6b) exhibit a maximum in the pre-midnight region, equatorward of the electron precipitation, producing the multiple arc structures seen in several WIC frames in Fig. 4. At dusk, the ion precipitation extends into the dayside, whereas on the dawnside it is confined to the nightside. The peak magnitude of the ion energy flux is approximately a factor of two lower than for the electrons. The correlation between ion precipitation and downward field-aligned currents is not strong. On the duskside, the ion precipitation coexists with the downward Birkeland currents, but on the dawnside the ion precipitation overlaps with upward currents. Kamide et al. (1979) argued that in the diffuse auroral region for a given energy protons carry less than $1 \%$ of the field-aligned currents carried by electrons and suggest that the downward Birkeland currents are carried by upward flowing thermal electrons instead. The low correlation between the ion precipitation and downward field-aligned currents observed here is consistent with this scenario.

Electromagnetic and particle energy deposition differ not only in their spatial distribution but also in their integrated intensity. The integrated EM energy flux poleward of $60^{\circ}$ MLAT (Fig. 5c) is $47 \mathrm{GW}$. The comparisons with DMSP observations show that the integrated EM energy flux is in each case approximately four times larger than we estimate from Iridium/SuperDARN. Applying this factor, our best estimate for the hemispheric EM power is $188 \mathrm{GW}$. On the other hand, the total energy flux from particle precipitation 
integrated over the same region is $20 \mathrm{GW}$, so that the hemispheric EM power is about ten times larger than that from particle precipitation. This result is consistent with the spread of ratios determined from statistical analysis of magnetic field observations by Ahn et al. (1983) albeit a bit higher than the ratio of four inferred by Lu et al. (1995) for the period 28-29 March 1992, using the AMIE technique (Richmond and Kamide, 1988). Interestingly, our result for this interval is consistent with the factor of eight difference found during the strongly northward IMF interval for a sunlit ionosphere discussed by Korth et al. (2005).

Both the EM and particle energy flux estimates are associated with significant uncertainties. For the determination of the EM power, the sources of error include those intrinsic to the Iridium/SuperDARN technique discussed above and the fact that the scale factor is determined along two DMSP trajectories only and cannot be verified globally. Nevertheless, we can establish lower and upper limits for these uncertainties. The gaps in the data sampling and the limited spatial resolution of the Iridium and SuperDARN fits lead necessarily to an underestimate of the global EM power. It is therefore reasonable to assume that the EM energy deposition of $47 \mathrm{GW}$ determined without the scale factor applied presents a lower limited to the analysis. An upper limit can be established from the partitioning of the EM energy deposition with respect to the spatial scales. We found that the resolution of Iridium and SuperDARN fits captures on average $88 \%$ of the EM energy deposition determined from the DMSP observation. Thus the upper limit the total EM energy deposition during the interval of our study is $12 \%$ higher $(211 \mathrm{GW})$ than our best estimate. On the other hand, the uncertainty for the particle energy flux is determined by the accuracy of the theoretical relations (Brittnacher et al., 1997; Germany et al., 1998) between the energy of the precipitating population and the photon energy flux. Frey et al. (2003) found that the particle energy flux derived from the IMAGE FUV auroral images and that measured in-situ typically differs by up to a factor of two. This assessment is consistent with the discrepancies observed between IMAGE and DMSP on the duskside, albeit the difference at dawn is somewhat larger. The true hemispheric power for the particle precipitation is thus somewhere in the range between $10 \mathrm{GW}$ and $40 \mathrm{GW}$.

While the ratio of electromagnetic and particle energy flux may be readily derived from the observations, caution is advised in inferring the relative effectiveness of the two energy forms on the physics of the thermosphere-ionospheremagnetosphere system from these results. The energy conversion processes are not only very distinct in their nature but also occur at different the altitudes. Most of the electromagnetic energy is dissipated in the lower ionosphere, where it mainly heats ions and neutrals, and also does work in moving the neutral atmosphere. This is clearly important for ionosphere-thermosphere coupling. On the other hand, particle energy flux is dissipated at higher altitudes, where ions and electrons are preferentially heated, rather than neutrals.
This may therefore have a greater effect on magnetosphereionosphere coupling via conductivity changes, and enhanced mass outflows. Therefore, although the particle energy flux may be lower in magnitude, it may have a greater effect on the ionosphere.

\section{Summary}

In this study we have estimated the large-scale EM and particle energy flux distributions to determine their relative locations and intensities. In comparison with DMSP in-situ observations we have confirmed that the Iridium/SuperDARN technique to determine the EM energy flux reliably locates the regions of enhanced EM energy deposition provided: (1) the Iridium and SuperDARN data are globally distributed and have sufficient sample density; (2) the energy deposition of interest occurs on spatial scales exceeding the halfwavelength latitude resolution of the spherical harmonic fits; and (3) the morphology of the magnetic perturbations and the electric field are stable over the length of the sample period. We have found that the morphology of the EM energy flux for the event presented here is adequately represented by the Iridium/SuperDARN technique, but its overall magnitude is approximately a factor of four low. Correcting for this underestimate, the EM energy flux is found to be nearly ten times the energy flux from auroral particle injection, consistent with previous studies. It is particularly interesting that the EM flux is dominant even for a dark ionosphere for which one expects an enhancement of auroral precipitation. The spatial distributions of EM and particle flux differ significantly with proton precipitation being strongest in regions usually associated with diffuse precipitation whereas the electron deposition correlates with regions of upward Birkeland current. Analyses of the energy inputs for a range of conditions will allow quantitative generalization of these results and provide a robust description of these energy inputs to the high-latitude I-T system.

Acknowledgements. We thank Iridium Satellite LLC for providing the engineering magnetometer data for scientific analysis. Support for processing and analysis of the Iridium magnetometer data was provided by NSF under grants ATM-9819804, ATM-0101064, and ATM-0334668 and by NASA under grants NAG5-10849 and NAG5-12303. Any opinions, findings, and conclusions or recommendations expressed in this material are those of the author(s) and do not necessarily reflect the views of the National Science Foundation and/or NASA. We thank the ACE team for the use of the MAG and SWEPAM data made available via the ACE Level 2 data base and acknowledge the Center for Space Sciences at the University of Texas at Dallas and the US Air Force for providing the DMSP thermal plasma data. Fred Rich provided the DMSP magnetometer data. Furthermore, we thank Dave Hardy, Fred Rich, and Patrick Newell for providing the DMSP particle data. Finally, we thank Jo Baker for providing software for displaying the SuperDARN convection patterns. 
Topical Editor M. Pinnock thanks three anonymous referees for their help in evaluating this paper.

\section{References}

Ahn, B.-H., Akasofu, A.-I., and Kamide, Y.: The joule heat production rate and the particle energy injection rate as a function of the geomagnetic indices AE and AL, J. Geophys. Res., 88, 6275-6287, 1983.

Anderson, B. J., Gary, J. B., Potemra, T. A., Frahm, R. A., Sharber, J. R., and Winningham, J. D.: UARS observations of Birkeland currents and Joule heating rates for the November 4, 1993 storm, J. Geophys. Res., 103, 26 323-26 335, 1998.

Anderson, B. J., Takahashi, K., and Toth, B. A.: Sensing global Birkeland currents with Iridium engineering magnetometer data, Geophys. Res. Lett., 27, 4045-4048, 2000.

Arnoldy, R. L.: Auroral particle precipitation and Birkeland currents, Rev. Geophys. Space Phys., 12, 217-231, 1974.

Brittnacher, M., Elsen, R., Parks, G., Chen, L., Germany, G., and Spann, J.: A dayside auroral energy deposition case study using the Polar Ultraviolet Imager, Geophys. Res. Lett., 24, 991-994, 1997.

Burns, A. G., Killeen, T. L., Wang, W., and Roble, R. G.: The solarcycle-dependent response of the thermosphere to geomagnetic storms, J. Atmos. Sol. Terr. Phys., 66, 1-14, 2004.

Cole, K. D.: Joule Heating of the Upper Atmosphere, Aust. J. Phys., 15, 221-235, 1962.

Cole, K. D.: Energy deposition in the thermosphere caused by the solar wind, J. Atmos. Terr. Phys., 37, 939-949, 1975.

Drayton, R. A., Koustov, A. V., Hairston, M. R., and Villain, J.P.: Comparison of DMSP cross-track ion drifts and SuperDARN line-of-sight velocities, 23, 2479-2486, 2005.

Evans, D. S., Maynard, N. C., Troim, J., Jacobsen, T., and Egeland, A.: Auroral vector electric field and particle comparisons. II. Electrodynamics of an arc, J. Geophys. Res., 82, 2235-2249, 1977.

Frey, H. U., Mende, S. B., Carlson, C. W., Gerard, J.-C., Hubert, B., Spann, J., Gladstone, R., and Immel, T. J.: The electron and proton aurora as seen by IMAGE-FUV and FAST, Geophys. Res. Lett., 28, 1135-1138, 2001.

Frey, H. U., Mende, S. B., Immel, T. J., Gérard, J.-C., Hubert, B., Habraken, S., Spann, J., Gladstone, G. R., Bisikalo, D. V., and Shematovich, V. I.: Summary of Quantitative Interpretation of IMAGE Far Ultraviolet Auroral Data, Space Sci. Rev., 109, 255283, 2003

Fujii, R., Nozawa, S., Buchert, S. C., and Brekke, A.: Statistical Characteristics of Electromagnetic Energy Transfer Between the Magnetopshere, the Ionosphere, and the Thermosphere, J. Geophys. Res., 104, 2357-2365, 1999.

Gary, J. B., Heelis, R. A., Hanson, W. B., and Slavin, J. A.: FieldAligned Poynting Flux Observations in the High-Latitude Ionosphere, J. Geophys. Res., 99, 11 417-11 427, 1994.

Gary, J. B., Heelis, R. A., and Thayer, J. P.: Summary of FieldAligned Poynting Flux Observations From DE 2, Geophys. Res. Lett., 22, 1861-1864, 1995.

Gérard, J.-C., Hubert, B., Meurant, M., Shematovich, V. I., Bisikalo, D. V., Frey, H., Mende, S. B., Gladstone, G. R., and Carlson, C. W.: Observations of the proton aurora with IMAGE
FUV imager and simultaneous ion flux in situ measurements, J. Geophys. Res., 106, 28 939-28 948, 2001.

Germany, G. A., Torr, D. G., Richards, P. G., and Torr, M. R.: Use of FUV auroral emissions as diagnostic indicators, J. Geophys. Res., 99, 23 297-23 305, 1994.

Germany, G. A., Spann, J. F., Parks, G. K., Brittnacher, M. J., Elsen, R., Chen, L., Lummerzheim, D., and Rees, M. H.: Auroral Observations from the Polar Ultraviolet Imager (UVI), In Geospace Mass and Energy Flow: Results from the International SolarTerrestrial Physics Program (J. L. Horwitz, D. L. Gallagher, and W. K. Peterson, Eds.), Geophysical Monograph 104, p. 149, American Geophysical Union, Washington, 1998.

Greenwald, R. A., Baker, K. B., Dudeney, J. R., Pinnock, M., Jones, T. B., Thomas, E. C., Villain, J.-P., Cerisier, J.-C., Senior, C., Hanuise, C., Hunsucker, R. D., Sofko, G., Koehler, J., Nielsen, E., Pellinen, R., Walker, A. D. M., Sato, N., and Yamagishi, H.: DARN/SuperDARN: A global view of high-latitude convection, Space Sci. Rev., 71, 763-796, 1995.

Guo, W., McEwen, D. J., Clemmons, J. H., and Luehr, H.: Birkeland currents associated with optical aurora, Adv. Space Res., 23, 1653-1656, 1999.

Haerendel, G., Frey, H. U., Rieger, O. H. B. E., Clemmons, J., Boehm, M. H., Wallis, D. D., and Lühr, H.: Inverted-V events simultaneously observed with the Freja satellite and from the ground, Geophys. Res. Lett., 21, 1891-1894, 1994.

Hardy, D. A., Schmitt, L. K., Gussenhoven, M. S., Marshall, F. J., Yeh, H. C., Shumaker, T. L., Hube, A., and Pantazis, J.: Precipitating electron and ion detectors (SSJ/4) for the block 5D/flights 6-10 DMSP satellites: Calibration and data presentation, Tech. Rep. AFGL-TR-84-0317, Air Force Geophys. Lab., Hanscom Air Force Base, Mass., 1984.

Hardy, D. A., Gussenhoven, M. S., and Brautigam, D.: A statistical model of auroral ion precipitation, J. Geophys. Res., 94, 370 392, 1989.

Hardy, D. A., McNeil, W., Gussenhoven, M. S., and Brautigam, D.: A statistical model of auroral ion precipitation. 2. Functional representation of the average patterns, J. Geophys. Res., 96, 55395547, 1991.

Hubert, B., Gérard, J.-C., Evans, D. S., Meurant, M., Mende, S. B., Frey, H. U., and Immel, T. J.: Total electron and proton energy input during auroral substorms: Remote sensing with IMAGEFUV, J. Geophys. Res., 107, SMP15-1-12, 2002.

Iijima, T. and Potemra, T. A.: Amplitude Distribution of FieldAligned Currents at Northern High Latitudes Observed by TRIAD, J. Geophys. Res., 81, 2165-2174, 1976.

Iijima, T. and Potemra, T. A.: Large-Scale Characteristics of FieldAligned Currents Associated With Substorms, J. Geophys. Res., 83, 599-615, 1978.

Kamide, Y. and Akasofu, S.-I.: The location of the field-aligned currents with respect to discrete auroral arcs, J. Geophys. Res., 81, 3999-4003, 1976.

Kamide, Y., Murphree, J. S., Anger, C. D., Berkey, F. T., and Potemra, T. A.: Nearly simultaneous observations of fieldaligned currents and visible auroras by the Triad and Isis 2 satellites, J. Geophys. Res., 84, 4425-4431, 1979.

Korth, H., Anderson, B. J., Wiltberger, M. J., Lyon, J. G., and Anderson, P. C.: Intercomparison of Ionospheric Electrodynamics From the Iridium Constellation With Global MHD Simulations, J. Geophys. Res., 109, A07 307, doi:10.1029/2004JA010428, 
2004.

Korth, H., Anderson, B. J., Frey, H. U., and Waters, C. L.: HighLatitude Electromagnetic and Particle Energy Flux During an Event With Sustained Strongly Northward IMF, Ann. Geophys., 23, 1295-1310, 2005, http://www.ann-geophys.net/23/1295/2005/.

Korth, H., Anderson, B. J., Wiltberger, M. J., Lyon, J. G., and Anderson, P. C.: Comparison of Birkeland Current Observation During Two Magnetic Cloud Events With MHD Simulations, Ann. Geophys., 26, 499-516, 2008, http://www.ann-geophys.net/26/499/2008/.

Lu, G., Richmond, A. D., Emery, B. A., and Roble, R. G.: Magnetosphere-Ionosphere-Thermosphere Coupling: Effect of Neutral Winds on Energy Transfer and Field-Aligned Current, J. Geophys. Res., 100, 19643-19659, 1995.

Lu, G., Baker, D. N., McPherron, R. L., Farrugia, C. J., Lummerzheim, D., Ruohoniemi, J. M., Rich, F. J., Evans, D. S., Lepping, R. P., Brittnacher, M., Li, X., Greenwald, R. A., Sofko, G., Villain, J., Lester, M., Thayer, J. P., Moretto, T., Milling, D., Troshichev, O., Zaitzev, A., Odintzov, V., Makarov, G., and Hayashi, K.: Global energy deposition during the January 1997 magnetic cloud event, J. Geophys. Res., 103, 11 685-11694, 1998.

Lummerzheim, D., Brittnacher, M., Evans, D., Germany, G. A., Parks, G. K., Rees, M. H., and Spann, J. F.: High Time Resolution Study of the Hemispheric Power Carried by Energetic Electrons Into the Ionosphere During the May 19/20, 1996 Auroral Activity, Geophys. Res. Lett., 24, 987-990, 1997.

McComas, D. J., Bame, S. J., Barker, P. L., Feldman, W. C., Phillips, J. L., Riley, P., and Griffee, J. W.: Solar Wind Electron Proton Alpha Monitor (SWEPAM) for the Advanced Composition Explorer, Space Sci. Rev., 86, 563-612, 1998.

Mishin, E. V., Burke, W. J., Huang, C. Y., and Rich, F. J.: Electromagnetic wave structures within subauroral polarization streams, J. Geophys. Res., 108, 1309, doi:10.1029/2002JA009793, 2003.

Murr, D. L. and Hughes, W. J.: Reconfiguration timescales of ionospheric convection, Geophys. Res. Lett., 28, 2145-2148, 2001.

Newell, P. T.: Reconsidering the inverted-V particle signature: Relative frequency of large-scale electron acceleration events, J. Geophys. Res., 105, 15 779-15 794, 2000.

Newell, P. T., Wing, S., Sotirelis, T., and Meng, C.-I.: Ion aurora and its seasonal variations, J. Geophys. Res., 110, A01 215, doi: 10.1029/2004JA010743, 2005.
Rees, M. H., Lummerzheim, D., Roble, R. G., Winningham, J. D., Craven, J. D., and Frank, L. A.: Auroral Energy Deposition Rate, Characteristic Electron Energy, and Ionospheric Parameters Derived From Dynamics Explorer 1 Images, J. Geophys. Res., 93, 12 841-12 860, 1988.

Richmond, A. D. and Kamide, Y.: Mapping electrodynamic features of the high-latitude ionosphere from localized observations: Technique, J. Geophys. Res., 93, 5741-5759, 1988.

Roble, R. G. and Rees, M. H.: Time-dependent studies of the aurora: Effects of particle precipitation on the dynamic morphology of ionospheric and atmospheric properties, Planet. Space Sci., 25, 991-1010, 1977.

Ruohoniemi, J. M. and Baker, K. B.: Large-scale imaging of highlatitude convection with Super Dual Auroral Radar Network HF radar observations, J. Geophys. Res., 103, 20 797-20 811, 1998.

Sharber, J. R., Frahm, R. A., Link, R., Crowley, G., Winningham, J. D., Gaines, E. E., Nightingale, R. W., Chenette, D. L., Anderson, B. J., and Gurgiolo, C. A.: UARS particle environment monitor observations during the November 1993 storm: Auroral morphology, spectral characterization, and energy deposition, J. Geophys. Res., 103, 26 307-26322, 1998.

Shepherd, S. G. and Ruohoniemi, J. M.: Electrostatic potential patterns in the high-latitude ionosphere constrained by SuperDARN measurements, J. Geophys. Res., 105, 23 005-23 014, 2000.

Smith, C. W., L'Heureux, J., Ness, N. F., Acuña, M. H., Burlaga, L. F., and Scheifele, J.: The ACE Magnetic Fields Experiment, Space Sci. Rev., 86, 613-632, 1998.

Thayer, J. P.: High-latitude currents and their energy exchange with the ionosphere-thermosphere system, J. Geophys. Res., 105, $23015-23024,2000$.

Waters, C. L., Anderson, B. J., and Liou, K.: Estimation of global field aligned currents using the Iridium System magnetometer data, Geophys. Res. Lett., 28, 2165-2168, 2001.

Waters, C. L., Anderson, B. J., Greenwald, R. A., Barnes, R. J., and Ruohoniemi, J. M.: High Latitude Poynting Flux From Combined Iridium and SuperDARN Data, Ann. Geophys., 22, 28612875, 2004, http://www.ann-geophys.net/22/2861/2004/. 